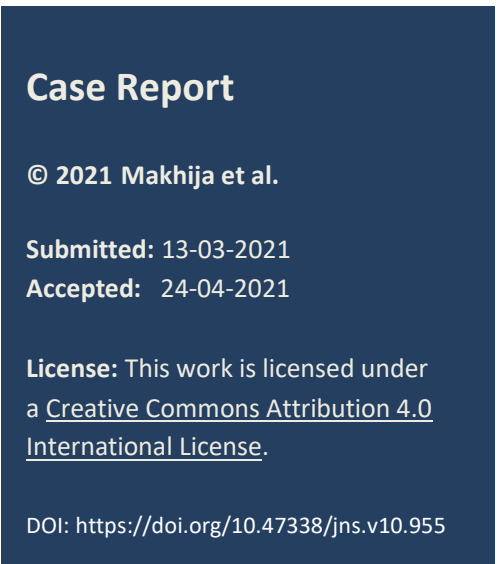

\title{
Upper pouch oesophageal duplication cyst- $A$ rare association with Tracheoesophageal fistula: A case report
}

Deepa P. Makhija, ${ }^{*}$ Manish P. Khobragade, Abhijit Kumar, Rujuta S. Shah, Kedar P. Mudkhedkar, Rahul K. Gupta, Beejal V. Sanghvi, Sandesh V. Parelkar

Department of Paediatric Surgery, Seth G.S. Medical College and KEM Hospital, Mumbai, India

Correspondence*: Dr. Deepa P. Makhija, Department of Paediatric Surgery, Seth G.S. Medical College and KEM Hospital, Mumbai, India. E-mail: deepee.sweety@gmail.com

\section{INTRODUCTION}

The majority of oesophageal duplication cysts are diagnosed at an older age. This is the fourth reported case in literature, wherein the duplication was recognized and successfully managed in the neonatal age at primary thoracotomy for TEF repair. The previous three reports had a cyst near the distal oesophagus. The index case is the first reported case with duplication cyst at the upper oesophageal pouch in a low-birth-weight neonate managed concomitantly at the time of primary repair.

\section{CASE REPORT}

A $1.5 \mathrm{~kg}$ one-day-old female was admitted with Type C TEF. At right thoracotomy done by posterolateral approach, the upper oesophageal pouch was blind, and the fistula was identified. The upper pouch looked hypertrophied. On manipulating the transoral red rubber tube, a spherical cyst was identified over the anterolateral aspect of the upper pouch (Fig 1). It was $2 \mathrm{~cm}$ in diameter, with well-defined margins without any communication with the oesophageal lumen. Excision of the cyst was done preserving the adjacent upper pouch. It contained clear mucinous fluid. The fistula was suture ligated and divided with an oesophago- oesophageal anastomosis.

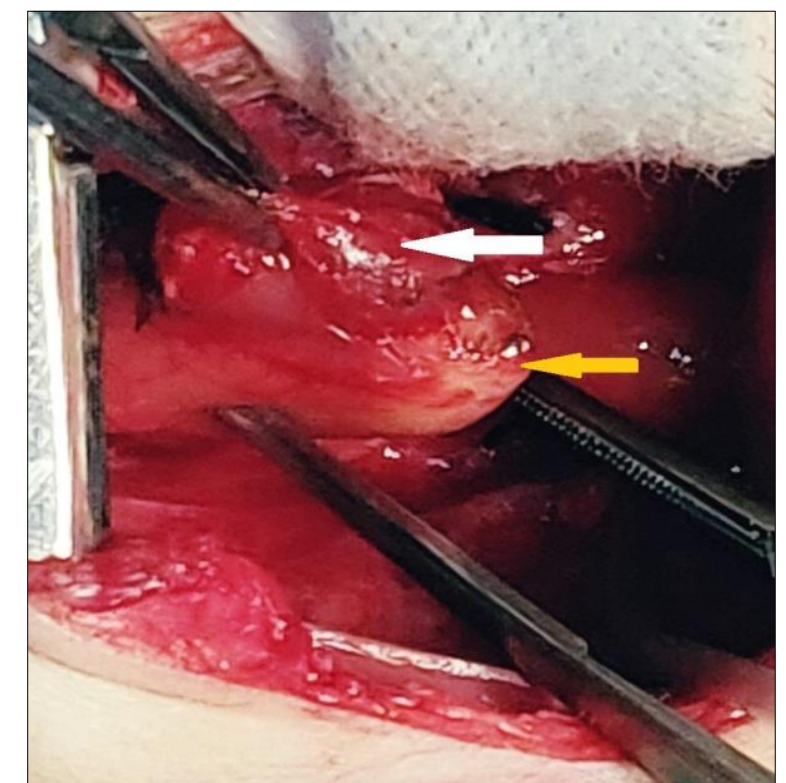

Figure 1: Intraoperative picture showing duplication cyst (white arrow) at the distal end of the upper pouch (yellow arrow)

Histopathology confirmed an oesophageal duplication cyst with a lining of squamous epithelium and a twolayered arrangement of smooth muscle bundles (Fig 2). The postoperative recovery was uneventful, with a normal oesophagogram study on day 5 and the child was discharged on the tenth day. The child is well at follow-up of 4.5 months. 


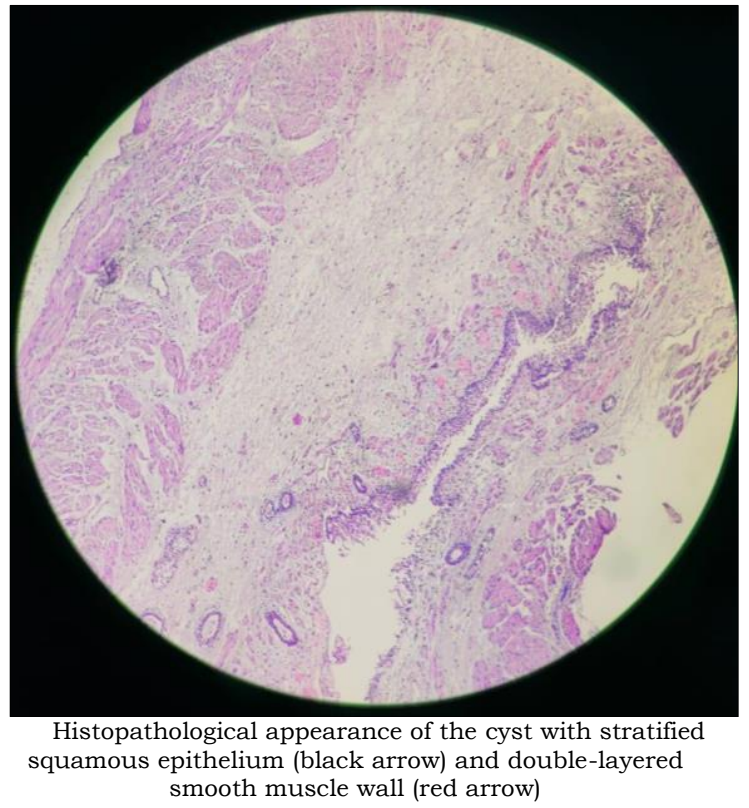

DISCUSSION

Oesophageal cysts account for about 10 to $15 \%$ of all duplication cysts in the gastrointestinal tract.[1] The incidence of oesophageal duplication cysts was estimated to be 1 in 8,200 patients in an autopsy series of nearly 50,000 patients.[1]

Most cysts are asymptomatic. Compression of the surrounding structures can lead to signs and symptoms of airway obstruction, dysphagia, or vascular compression. The cysts can develop infection or haemorrhage due to peptic ulceration of the ectopic gastric mucosa. Rarely malignant degeneration can happen. Excision is the treatment of choice for paediatric foregut duplication cysts due to the risk of haemorrhage, infection, external compression, and in rare cases, malignant transformation.
The histopathological criteria for classifying an oesophageal cyst as developed by Arbona et al. [2] are:

1. The cyst is within or attached to the oesophageal wall.

2. It is covered by two muscle layers.

3. The lining is the squamous, columnar, cuboidal, pseudostratified, or ciliated epithelium.

The association of OA and TEF with oesophageal duplication is suggested to have a common embryological derivation since both have origin from the foregut. $[3,4]$ Faulty separation of the ventral laryngotracheal tube is presumed to lead to Oesophageal atresia and/or tracheooesophageal fistula.[4] Abnormal outpouching of endoderm from the primitive foregut wall causes oesophageal duplication cysts. This ectopic endoderm loses its communication with the oesophageal lumen and a non-communicating mass with accumulated secretions is formed. This unifying etiologic concept of the various bronchopulmonary foregut malformations is explained by the common embryologic pathogenesis. This concept explains how this group of anomalies may occur in any combination. [4]

Of the seventeen cases previously reported of the foregut duplication cyst associated with OA with or without TEF; in only three cases, the foregut duplication cyst was found and dealt with simultaneously.[57] The index case is the fourth case managed at the time of primary repair and the first one in association with the upper pouch. The adjacent oesophageal structure could be preserved on account of the local anatomy. Unrecognized, this could have possibly led to a failed anastomosis or dysphagia later on. Table 1 has a summary of cases that have been managed at the time of primary repair.

Table 1: Summary of cases managed at the time of primary repair

\begin{tabular}{|l|l|l|l|l|}
\hline Publication & Age \& weight & Type of TEF & Size and Location of cyst & $\begin{array}{l}\text { Management concomitant with } \\
\text { TEF repair }\end{array}$ \\
\hline Narsimharao et. al. (1987) & 1-day, 2.6 kg & Type C & 2cm, Lower segment & $\begin{array}{l}\text { Segmental resection of the } \\
\text { involved segment }\end{array}$ \\
\hline Knod et. al. (2013) & $\begin{array}{l}\text { 2-day, weight not } \\
\text { available }\end{array}$ & Type C & 0.6cm, Lower segment & $\begin{array}{l}\text { Enucleation attempted but a short } \\
\text { segmental resection was done } \\
\text { because of ischemia of the } \\
\text { adjacent oesophageal wall }\end{array}$ \\
\hline Spataru et. al. (2015) & 1-day, 2.82kg & Type C & 2cm, Lower segment & Excision done \\
\hline Index case (2020) & 1-day, 1.5 kg & Type C & $\begin{array}{l}\text { 2cm, Upper pouch distal end } \\
\text { (Mid oesophagus) }\end{array}$ & Excision done \\
\hline
\end{tabular}

The location of the foregut duplication cyst with respect to the oesophagus is an important contributory factor in detecting and treating it. As only three previously reported cysts have been diagnosed at initial surgery, a connection between them does not help in earlier diagnosis. As per a study by Knod et al [6] in cases where the foregut duplication cyst was missed at initial surgery, 2.8 operations on average were required before successful cyst management. The mean age at cyst diagnosis was 17.8 months, ranging from 1 day to 7 years. The infrequency of concomitantly detected and treated foregut duplication cysts may be 
on account of limited oesophageal mobilisation during the oesophageal atresia repair leading to poor and restricted visibility of the operative field.[6]

To conclude, Upper pouch oesophageal duplication with TEF is very rare and this is only the fourth case managed concomitantly at primary surgery in English literature available. Being aware of this association may help preclude a second thoracotomy.

\section{REFERENCES}

1. Kawashima S, Segawa O, Kimura S, Tsuchiya M, Henmi $\mathrm{N}$, Hasegawa $\mathrm{H}$, et al. A case of cervical esophageal duplication cyst in a newborn infant. Surg Case Rep. 2016; 2:1-7.

2. Arbona JL, Fazzi JG, Mayoral J. Congenital esophageal cysts: case report and review of literature. Am J Gastroenterol. 1984; 79:177-82.

3. Tröbs RB, Barenberg K, Vahdad MR, Tannapfel A. Noncommunicating tubular duplication of the upper pouch in esophageal atresia without fistula. J Pediatr Surg. 2009; 44:1646-8.

\section{Acknowledgements: Nil}

Conflict of Interest: Authors have no conflict of interest. Source of Support: Nil

Consent to Publication: Author(s) declared taking informed written consent for the publication of clinical photographs/material (if any used), from the legal guardian of the patient with an understanding that every effort will be made to conceal the identity of the patient, however it cannot be guaranteed.

Author Contributions: Author(s) declared to fulfil authorship criteria as devised by ICMJE and approved the final version.

4. Kirks DR, Filston HC. The association of esophageal duplication cyst with esophageal atresia. Pediatr Radiol. 1981; 11:214-6.

5. Narasimharao KL, Mitra SK. Esophageal atresia associated with esophageal duplication cyst. J Pediatr Surg. 1987; 22:984-5.

6. Knod JL, Garrison AP, Frischer JS, Dickie B. Foregut duplication cyst associated with esophageal atresia and tracheoesophageal fistula: a case report and literature review. J Pediatr Surg. 2013; 48:e5-7.

7. Spataru RI, Popoiu MC, Ivanov M. Foregut duplication cyst associated with esophageal atresia-one-stage neonatal surgical repair. Indian J Surg. 2015; 77:52-5. 